\title{
Political viability of public pensions and education. An empirical application
}

\author{
Gianko Michailidis*1 and Concepció Patxot ${ }^{\dagger 1}$ \\ ${ }^{1}$ University of Barcelona, Av. Diagonal 696, Barcelona, 08034, Spain
}

\begin{abstract}
Public intergenerational transfers (IGTs) may emerge from the failure of private arrangements to provide optimal economic resources for the young and old. We investigate the political sustainability of the public system of IGTs by seeking to determine the outcome if the decision to reallocate economic resources per se was put to the vote. Exploiting the particular nature of the data from the National Transfer Accounts and the political economy application of Rangel (2003), we show that most of the developed countries would vote in favor of a joint public education and pension system. Interestingly, political support is strengthened when we account for population ageing.
\end{abstract}

JEL Classification: D70, H50, J10, P16.

Keywords: Intergenerational Transfers; Population Ageing; Pay-As-You-Go Financing; National Transfer Accounts; Political Economy.

\section{Introduction}

The biological fact that people are physically dependent on others, especially during childhood and old age, has been tackled in a variety of ways. Traditionally, these dependency needs have been addressed within the family via private transfers, but gradually the latter have been substituted by the market (asset-based reallocations) and public transfers.

The literature on public intergenerational transfers (henceforth, IGTs) is extensive, yet somewhat fragmented. It can be traced back to initial studies that sought to determine the golden rule of capital accumulation in the standard overlapping generation framework (Diamond, 1965). Against this backdrop, abstracting from altruism and the consideration of young dependents, the failure of the competitive economy to meet the golden rule has created a role for public IGTs financed via capitalization (pay-as-you-go) in situations of under(over)-accumulation.

\footnotetext{
${ }^{*}$ Corresponding author, e-mail: g.michailidis@ub.edu, Tel:(+34)934024312.

†e-mail: cio.patxot@ub.edu, Tel:(+34)934021864.
} 
Later, probably as a result of the demographic transition, this literature struck out in a number of new directions. Here, various authors stress that besides the elderly, children are also dependent. ${ }^{1}$ Considering the both sides of dependency Becker and Murphy (1988) argue that the need for government intervention might derive from the failure of the markets and intra-family reallocations to achieve optimal investments in human capital for the young and pensions for the old.

As a result, the connection between transfers to children and to the elderly (which have always been present in the family) has arisen in the public sphere. More specifically, various authors [Pogue and Sgontz (1977); Konrad (1995); Kemnitz (2000)] highlight the fact that the pay-as-yougo (PAYG) pension system creates appropriate incentives for the middle-aged to invest in public education, since it enhances the income of future working generations. Interestingly, this in turn generates a motive to promote education as a means to improve the financial sustainability of the PAYG-financed pension system in the face of demographic ageing.

From the perspective afforded by the political economy, what matters is political sustainability. Within this framework, Rangel (2003) develops the conditions under which the combination of two exchange programs (IGTs towards young and old) would be sustained (voted) in a cooperative game, played by non-altruistic agents. In this paper, we employ the National Transfer Accounts (NTA) data to test this possibility in the case of a linked system of pensions and education. ${ }^{2}$

The remainder of the paper proceeds as follows. Section 2 presents the data and methodology. Section 3 provides the results. The last section contains concluding remarks.

\section{Data \& Methodology}

\subsection{NTA Data}

In contrast to conventional methods for describing IGTs that use annual flows as a share of GDP, we exploit the specific structure of the NTA data. This provides us with a complete, systematic and coherent accounting of economic flows from working age groups to dependent groups. Figure 1 shows how the age profile of the life cycle deficit (consumption minus labor income) is financed through net private and public transfers, where the residual is asset-based reallocations (asset income plus dissavings). Specifically, for our purposes, we combine the age profiles of benefits and taxes for education and pensions with population age structure. ${ }^{3}$

\footnotetext{
${ }^{1}$ Peters (1995) and Boldrin and Montes (2005) consider endogenous human capital and Bental (1989) and Abio et al. (2004) endogenous fertility.

${ }^{2}$ Bommier et al. (2010) more concerned with actuarial fairness rather than the political viability of public transfers, compute the present value in the US showing that the most of the generations have been benefited from the introduction of public transfers.

${ }^{3}$ NTA data are taken from Lee and Mason (2011) (http://www.ntaccounts.org/web/nta/show/Country\% 20Summaries). Austria(2000), Brazil(1996), CostaRica(2004), Finland(2004), Germany(2003), Hungary(2005), India(2004), Japan(2004), Mexico(2004), Slovenia(2004), S.Korea(2000), Spain(2000), Sweden(2003), Taiwan(1998), Thailand(2004), US(2003).
} 
Figure 1: Life Cycle Deficit, Public and Private IGTs on average for 16 countries. The higher the deficit, the greater the need for IGTs.

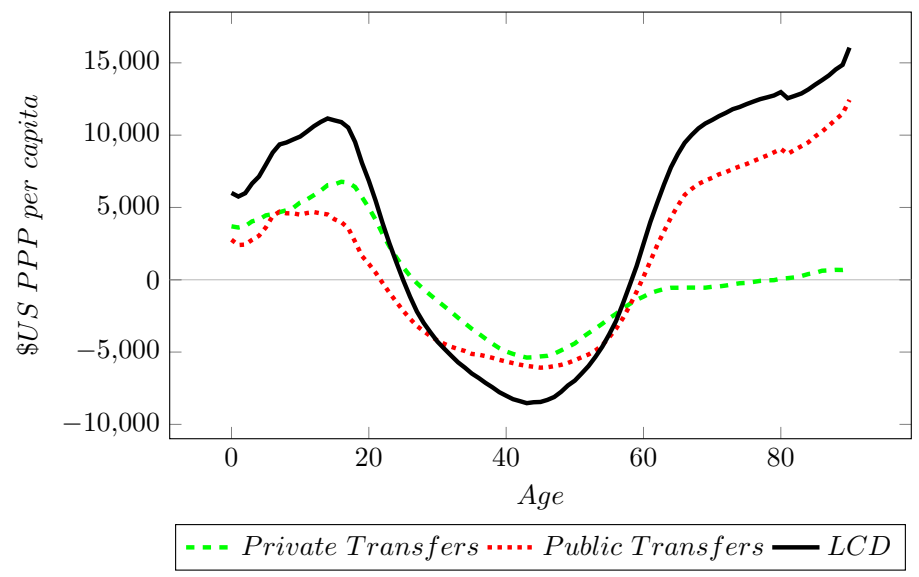

\subsection{Methodology}

The empirical exercise that we conduct follows the political economy application suggested by Rangel (2003). Agents live for nine decades $(a=1, \ldots, 9)$. Individuals are dependent children for two periods, working-age adults for five periods and retirees for a further two. Every period, society votes on the amount that it wishes to devote to the PAYG pension system. The system is financed solely by workers that have to pay a payroll tax $(T)$.

Cohorts cast a positive vote in favor of the pension system only if their own continuation value (henceforth, CV) is positive. The CV is the present value of the pension system for each age cohort, i.e., the present value of retirement benefits $(B)$ net of payroll taxes $(T)$, as shown in equation (1) for workers $a=3, \ldots, 7$ and (2) for retirees $a=8,9 .{ }^{4}$

$$
\begin{gathered}
C V_{a}=\sum_{i=8}^{9} \frac{B_{i}}{(1+r)^{i-a}}-\sum_{i=a}^{7} \frac{T_{i}}{(1+r)^{i-a}} \\
C V_{a}=\sum_{i=a}^{9} \frac{B_{i}}{(1+r)^{i-a}}
\end{gathered}
$$

All agents above the second cohort are allowed to vote. Thus, there are seven voting groups and to secure a majority only four are needed. Retirees always vote in favor of the current system (at their age they enjoy pension benefits without paying payroll taxes). Hence, age cohorts $a=3, \ldots, 7$ are the decisive voters. Provided the continuation values of at least two of these cohorts are positive, the majority votes for pensions.

Furthermore, to have a sustained system of linked IGTs, we also need to invest optimally in education $(E)$, through taxes imposed on workers and retirees. The link is assumed to be reinforced through trigger strategies played among generations. Thus, if (3) holds at least for cohorts $a=5, \ldots, 8$, the majority are willing to vote for the joint system (education and pensions), because this generates

\footnotetext{
${ }^{4}$ The real interest rate $(\mathrm{r})$ is taken from http://data.worldbank.org/indicator/FR.INR.RINR
} 
a CV that is bigger than the education tax they have to pay.

$$
C V_{a} \geqslant E P_{a}
$$

where $P_{a}$ is the relative size of each cohort. ${ }^{5}$

\section{$3 \quad$ Results}

Using (1) and (2) we gauge the CV for pensions for each voting cohort in a particular year for each country. The CVs for the $a=3,4$ age groups are negative for the vast majority of the countries selected. ${ }^{6}$ The interpretation is quite straightforward. Under dynamic efficiency, young workers are unwilling to support the pension system, because in terms of present value they receive fewer benefits than the taxes they pay. In contrast, and as expected, retirees fully support the system. Hence, cohorts $a=5, \ldots, 7$ are the decisive voters. The CVs of groups six and seven are positive for the majority of the countries considered. As shown in the baseline scenario (Table 1), in most countries the majority of votes are cast in favor of pensions. However, when we weight the votes by the population size of each cohort, the voting outcome is considerably worse. Only half the countries (mostly developed) vote for pensions (column 3).

As is obvious from (1) and (2) the value of the interest rate plays a key role in the calculation of the CV. We test how the results might change if all the countries had the same interest rate. As shown in column 4 , the results do not vary significantly from the previous case, probably reflecting the small differences in interest rates (except in Brazil).

Table 1: Voting Scenarios

\begin{tabular}{|c|c|c|c|c|c|c|c|c|c|c|}
\hline \multirow[b]{2}{*}{ Country } & \multicolumn{5}{|c|}{ Voting on Pensions } & \multicolumn{5}{|c|}{ Voting on Pensions and Education } \\
\hline & Baseline & VDS & VSIR & BY & WY & Baseline & VDS & VSIR & BY & WY \\
\hline Austria & 85,71 & 83,12 & 83,12 & 79,24 & 86,76 & 57,14 & 56,16 & 78,69 & 77,53 & 75,23 \\
\hline Brazil & 57,14 & 25,83 & 100,00 & 21,59 & 58,49 & 42,86 & 24,26 & 98,42 & 20,99 & 45,66 \\
\hline Costa Rica & 71,43 & 46,14 & 46,14 & 40,58 & 73,78 & 57,14 & 44,22 & 44,22 & 38,81 & 60,48 \\
\hline Finland & 71,43 & 65,85 & 65,85 & 51,48 & 69,87 & 57,14 & 61,49 & 61,49 & 50,24 & 58,08 \\
\hline Germany & 71,43 & 64,33 & 85,28 & 60,92 & 74,93 & 57,14 & 59,94 & 80,90 & 59,46 & 64,15 \\
\hline Hungary & 71,43 & 61,74 & 61,74 & 54,30 & 70,71 & 57,14 & 58,02 & 58,02 & 52,94 & 60,63 \\
\hline India & 57,14 & 24,26 & 24,26 & 21,85 & 55,37 & 42,86 & 23,40 & 23,40 & 21,13 & 46,62 \\
\hline Japan & 71,43 & 65,47 & 65,47 & 46,22 & 75,38 & 57,14 & 60,46 & 60,46 & 45,38 & 61,40 \\
\hline Mexico & 57,14 & 24,80 & 24,80 & 23,26 & 57,95 & 42,86 & 23,18 & 23,18 & 22,40 & 45,55 \\
\hline Slovenia & 71,43 & 61,75 & 61,75 & 54,41 & 73,04 & 57,14 & 58,60 & 58,60 & 52,76 & 61,93 \\
\hline S. Korea & 42,86 & 15,01 & 15,01 & 10,06 & 46,27 & 28,57 & 13,77 & 13,77 & 9,21 & 16,31 \\
\hline Spain & 71,43 & 57,97 & 57,97 & 49,91 & 73,92 & 57,14 & 53,65 & 53,65 & 48,25 & 61,79 \\
\hline Sweden & 71,43 & 64,74 & 64,74 & 56,99 & 70,01 & 57,14 & 58,55 & 58,55 & 54,82 & 58,30 \\
\hline Taiwan & 28,57 & 6,53 & 6,53 & - & - & 14,29 & 5,20 & 5,20 & - & - \\
\hline Thailand & 28,57 & 6,54 & 6,54 & 3,56 & 26,24 & 0,00 & 0,00 & 0,00 & 0,00 & 0,00 \\
\hline US & 71,43 & 59,95 & 59,95 & 52,07 & 68,71 & 42,86 & 34,17 & 34,17 & 31,96 & 42,71 \\
\hline $\begin{array}{l}\text { Note: Baselin } \\
\text { structure of the } \\
B Y(W Y) \text { : Best } \\
\text { Brazil(1950;2085 } \\
\text { Japan(1950;2051 }\end{array}$ & $\begin{array}{l}\text { CostaRica } \\
\text { Mexico(19 }\end{array}$ & f votes & cohor & $\overline{\text { resenta }}$ & I agent. & VDS: vote & $\overline{\text { centage }}$ & $\begin{array}{l}Y ; W Y \\
50 ; 205 \\
), \quad S w\end{array}$ & rved den & $\begin{array}{l}\text { graphic } \\
(4,2 \%) . \\
; 2060), \\
; 2100), \\
), \text { Tai- }\end{array}$ \\
\hline
\end{tabular}

The demographic transition is modifying the prospects of both financial and political sustainability. Columns 5 and 6 show the results of considering the "best" and "worst" years in terms of

\footnotetext{
${ }^{5}$ Note that cohort 9 votes against education.

${ }^{6} \mathrm{CVs}$ are not reported. Bohn (1999) finds similar results calculating the continuation value of PAYG social security in the US. He suggest that it is negative for the young voters but strictly positive for the voters above median voter age.
} 
the old dependency ratio (percentage of people aged 65+ over the working age population, aged 16-64). The results are better in terms of votes during the "worst" year. Intuitively, the political tenability of pensions is better in the worst case demographic situation (despite the direct negative effect on the financial health of the PAYG pensions), followed by the observed year (column 4) and the "best" year, in this order. This result is related to the "political power of the elderly" hypothesis according to which population ageing makes the median voter older and, hence, more inclined to support pro-pension policies (Browning, 1975). In our case older median voter means higher continuation value that can be invested in education making the joint system of pensions and education more sustained.

The next step is to test if a system in which generations link education to pensions is politically tenable. We subtract the education tax from the $\mathrm{CV}$ of the pensions to obtain the $\mathrm{CV}$ of the linked system for the age cohorts $a=3, \ldots, 8$ (see, 3 ). Table 1 shows that about half the countries examined would support such a system, when considering a representative voter for each cohort. The use of the same interest rate does not have a notable impact on the voting outcome (compared to column 8). However, when we consider the demographic transition (from column 10 to 8 and 11), more countries support or are close to supporting both pensions and education when population ages.

Figure 2: Intergenerational Transfers Structure and Life Cycle Deficit

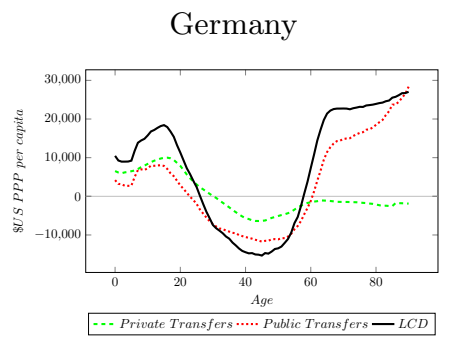

Taiwan

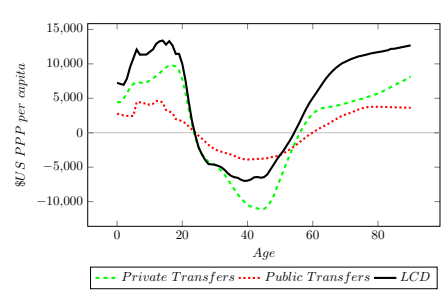

Sweden

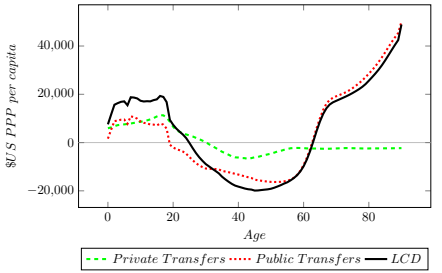

Thailand

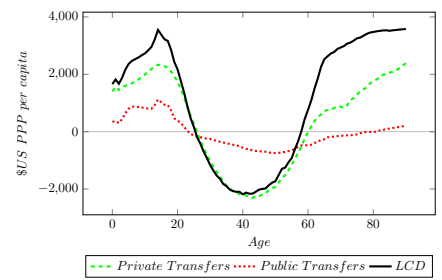

Spain

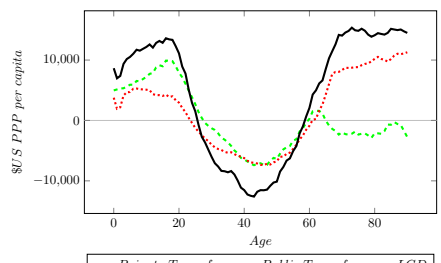

Philippines

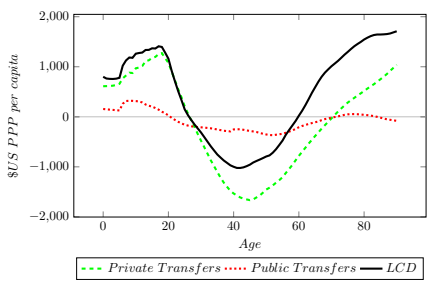

The observed differences among the countries in terms of political viability can be explained by the strength of the ageing process and the size of the welfare state. It turns out that when the latter is bigger it tends to crowd out private transfers to the elderly, creating higher incentives to vote for pensions and the combined system of pensions and education, as depicted in Figure 2 for selected countries (e.g., Germany, Sweden and Spain). In contrast, countries with relatively younger population where public transfers continue to be dominated by private transfers (e.g., Taiwan, Thailand and Philippines) have fewer political incentives to support the public system. 


\section{Conclusions}

Our results indicate that many countries would support the pension system (9 out of 16) and the joint system of pensions and education ( 8 out of 16). This is more likely to be true in countries with a strong ageing process and high level of public transfers which crowd out private transfers to the elderly.

In addition, although ageing pressure on the financial health of the PAYG pensions system points to a conflict between financial and political sustainability, our results indicate some positive signs. Population ageing means higher continuation value of pension system for the median voter. This can increase the investment in education and hence make the joint system of pensions and education more sustained. Thus, pensions can foster education. This in turn, might create a positive feedback. Hence, "pre-funding" pensions through educational expenditure might improve the financial prospects of the pensions PAYG system in an ageing world.

Further research is needed in order to investigate the extent to which the heterogeneity in the levels of private and public transfers across countries can be attributed to the cultural and/or institutional differences among countries.

\section{Acknowledgement}

This work was supported by the Spanish Science and Technology System (Project number ECO201678991-R MINECO/FEDER and the Red de excelencia SIMBIEN ECO2015-71981-REDT), the Catalan Government Science Network (Project number SGR2014-1257) and the network Xarxa de Referencia en $\mathrm{R}+\mathrm{D}+\mathrm{I}$ en Economia i Poltiques Publiques (XREPP), and the European Commission through Joint Programming Initiative (JPI) "More Years Better Lives (2016)", WELTRANSIM Project.

\section{References}

Abio, G., Mahieu, G., Patxot, C., 2004. On the optimality of payg pension systems in an endogenous fertility setting. Journal of Pension Economics and Finance 3 (1), 35-62.

Becker, G., Murphy, K., 1988. The family and the state. Journal of Law and Economics 31, 1-18.

Bental, B., 1989. The old age security hypothesis and optimal population growth. Journal of Political Economy 98, $12-37$.

Bohn, H., 1999. Will social security and medicare remain viable as the U.S. population is aging? Carnegie-Rochester Conference Series on Public Policy 50 (1), 1-53.

Boldrin, M., Montes, A., 2005. The intergenerational state: education and pensions. Review of Economic Studies 72, $651-664$

Bommier, A., Lee, R., Miller, T., Zuber, S., 2010. Who wins and who loses? Public transfer accounts for us generations born 1850-2090. Population and Development Review 36 (1), 1-26.

Browning, E., 1975. Why the social insurance budget is too large in a democracy. Economic Inquiry $13,373-378$. 
Diamond, P., 1965. National debt in a neoclassical growth model. American Economic Review 86 (3), 374-386.

Kemnitz, A., 2000. Social security, public education, and growth in a representative democracy. Journal of Population Economics 13, 443-462.

Konrad, K., 1995. Social security and strategic inter-vivos transfers of social capital. Journal of Population Economics $8,315-326$.

Lee, R., Mason, A., 2011. Population aging and the generational economy: A global perspective, Cheltenham: Edward Elgar, 2011.

Peters, W., 1995. Public pensions,family allowances and endogenous demographic change. Journal of Population Economics 8, 161-183.

Pogue, T., Sgontz, L., 1977. Social security and investment in human capital. National Tax Journal 30, 157-169.

Rangel, A., 2003. Forward and backward intergenerational goods: Why is social security good for the environment? American Economic Review 93, 813-834. 